Cite this: New J. Chem., 2014 38,437

Received (in Montpellier, France) 4th July 2013,

Accepted 4th November 2013

DOI: $10.1039 / c 3 n j 00736 g$

www.rsc.org/njc

\section{Influence of nitrogen donor ligands on the coordination modes of copper(II) 2-nitrobenzoate complexes: structures, DFT calculations and magnetic properties $\dagger$}

\author{
Raj Pal Sharma, ${ }^{\star a}$ Anju Saini, ${ }^{a}$ Divyakshi Monga, ${ }^{a}$ Paloth Venugopalan, ${ }^{a}$ \\ Julia Jezierska, ${ }^{b}$ Andrew Ozarowski ${ }^{c}$ and Valeria Ferretti*d
}

\begin{abstract}
Three novel copper(II) 2-nitrobenzoate complexes, [Cu( $\gamma$-pic) $\left.{ }_{2}(2-\text { nitrobenzoate) })_{2}\right]$ 1, [Cu( $\beta$-pic) 2 (2-nitrobenzoate) $\left.{ }_{2}\left(\mathrm{H}_{2} \mathrm{O}\right)_{2}\right] 2$ and $\left.\left[\mathrm{Cu}_{2}\left(\mathrm{H}_{2} \text { tea }\right)_{2} \text { (2-nitrobenzoate) }\right)_{2}\right] \cdot 2\left(\mathrm{H}_{2} \mathrm{O}\right) 3$ (where $\gamma$-pic = 4-methylpyridine, $\beta$-pic $=3$-methylpyridine and $\mathrm{H}_{2}$ tea $=$ mono deprotonated triethanolamine), were isolated by addition of $\gamma$-pic, $\beta$-pic and $\mathrm{H}_{3}$ tea to the hydrated copper(॥) 2-nitrobenzoate, $\left[\mathrm{Cu}_{2}(2 \text {-nitrobenzoate })_{4}\left(\mathrm{H}_{2} \mathrm{O}\right)_{2}\right] \cdot 2 \mathrm{H}_{2} \mathrm{O}$, suspended in a methanol:water (4:1) mixture. The newly synthesized complexes have been characterized by elemental analyses, thermogravimetric analysis (TGA), spectroscopic techniques (EPR, IR and UV/Visible), magnetic susceptibility measurements, single crystal $X$-ray structure determination and DFT study. All compounds crystallize in the monoclinic crystal system with the $P 2_{1} / c$ space group. $\mathrm{X}$-ray structure determination revealed the presence of monomers in both $\mathbf{1}$ and $\mathbf{2}$ and dimer in $\mathbf{3}$ with the deprotonated oxygen atom of the $\mathrm{H}_{2}$ tea ligand bridging two $\mathrm{Cu}\left({ }_{1}\right)$ atoms. Two co-crystallized water molecules are also present in 3 . The crystal lattice is stabilized by $\mathrm{C}-\mathrm{H} \ldots \mathrm{O}$ hydrogen bonding interactions in $\mathbf{1}$ and $\mathrm{O}-\mathrm{H} \ldots \mathrm{O}, \mathrm{C}-\mathrm{H} \ldots \mathrm{O}$ hydrogen bonding interactions in $\mathbf{2}$ and $\mathbf{3}$. The dimeric complex exhibits relatively strong ferromagnetic exchange with $\mathrm{J}=-100 \mathrm{~cm}^{-1}$ (corresponding to $H=J S_{1} S_{2}$ ). The zero-field splitting parameters (zfs) of the dimer triplet states $D$ and $E$ were derived from HF EPR spectra recorded at moderately low temperatures. The sign of $D$ was determined from low-temperature HF EPR spectra.
\end{abstract}

\section{Introduction}

In recent years, crystal engineering based on organic and/or inorganic molecular building blocks has been rapidly expanding owing to the novel and diverse topologies and potential applications in host-guest chemistry, catalysis, electrical conductivity and magnetism. ${ }^{1-6}$ One of the important strategies is to establish the likely connections between organic and/or inorganic molecular building blocks by exploiting non-covalent interactions. ${ }^{7,8}$

\footnotetext{
${ }^{a}$ Department of Chemistry, Panjab University, Chandigarh-160014, India. E-mail: rpsharma@pu.ac.in

${ }^{b}$ Faculty of Chemistry, University of Wroclaw, 50-383 Wroclaw, 14 F. Joliot Curie Str., Poland

${ }^{c}$ National High Magnetic Field Laboratory, Florida State University, Tallahassee, Florida 32310, USA

${ }^{d}$ Center for Structural Diffractometry and Department of Chemical and Pharmaceutical Sciences, University of Ferrara, via, Fossato di Mortara 17-27, I-44121, Ferrara, Italy. E-mail: frt@unife.it

$\dagger$ Electronic supplementary information (ESI) available: TGA, IR and UV characterization details, and figures depicting TGA curves, IR spectra and crystal packing for the three complexes. CCDC 915710 (1), 915711 (2) and 915712 (3). For ESI and crystallographic data in CIF or other electronic format see DOI: 10.1039/ c3nj00736g
}

In the case of transition metal complexes, these interactions are established mainly among the 'organic' parts of the molecules, and can be modulated through a suitable choice of the ligands. Copper(II) complexes are among the most widely studied coordination compounds because of their wide range of applications, ${ }^{9-15}$ in particular when the ligands are alkyl/aryl carboxylate anions, which can exhibit a wide variety of coordination modes (monodentate, symmetriclasymmetric chelating, and bidentatel monodentate bridging). Moreover, properties of copper(II) carboxylates and the coordination abilities of carboxylate ions can be varied to a large extent using nitrogen donor ligands with appropriate functionalization. ${ }^{16-19} \mathrm{~A}$ combined stereoelectronic effect that emerges as a result of both the carboxylate anion and the ancillary N-donor ligand would dictate the final nature and structure of the complex formed. That is, in a nutshell, the chosen carboxylate ligand may show a propensity to exhibit different coordination modes depending upon the type of N-donor ligand chosen.

In this direction, with the aim of comparing the structural and packing features of complexes in which different $\mathrm{N}$-donor ligands participate, we have chosen two very similar nitrogendonor ligands $\gamma$-pic (4-methyl pyridine) and $\beta$-pic (3-methyl 
pyridine) which are rigid in their molecular topology along with a third $\mathrm{N}$-donor ligand triethanolamine $\left(\mathrm{H}_{3}\right.$ tea $)$ which is highly flexible in terms of molecular conformation. This ligand after deprotonation (i.e. $\mathrm{H}_{2}$ tea) will be endowed with two-OH groups which may take part either singly or in a combined way in the hydrogen bonding as effective proton donors. In addition, a theoretical approach that can model these structures and their bonding features would be rewarding. Thus, this paper reports the synthesis, characterization and DFT study of three novel copper(II) complexes with different nitrogen donor ligands, $\left[\mathrm{Cu}(\gamma \text {-pic })_{2}(2 \text {-nitrobenzoate })_{2}\right]$ (1), $\left[\mathrm{Cu}(\beta \text {-pic })_{2}\right.$ (2-nitrobenzoate). $\left.2\left(\mathrm{H}_{2} \mathrm{O}\right)_{2}\right](2)$ and $\left[\mathrm{Cu}_{2}\left(\mathrm{H}_{2} \text { tea }\right)_{2}(2 \text {-nitrobenzoate })_{2}\right] \cdot 2\left(\mathrm{H}_{2} \mathrm{O}\right)(3)$.

Particular attention has been devoted to complex 3 where the presence of the $\mathrm{H}_{2}$ tea ligand favours the formation of a dinuclear molecule in which two $\mathrm{Cu}$ atoms are bridged by two oxygen atoms. In general, the magnetic behavior of transition metal complexes containing more than one metal atom with unpaired electrons is affected by the metal-metal interaction. The case discussed in this paper is that of weakly interacting metal ions (with the $\mathrm{Cu}$...Cu distance in the range 3-5 $\mathrm{A}$ ), where the coupling between their electrons leads to low-lying excited states of different spin which can be thermally populated. The resulting magnetic behavior can be antiferromagnetic or ferromagnetic, and the ferromagnetic/antiferromagnetic coupling is strictly related to structural parameters such as the $\mathrm{Cu}-\mathrm{O}-\mathrm{Cu}$ angle and the $\mathrm{Cu} \cdots \mathrm{Cu}$ distance. Accordingly, the magnetic characterization of $\mathbf{3}$ has been performed both from a theoretical and experimental point of view.

\section{Experimental}

Three copper(II) carboxylate complexes were synthesized by reacting copper(II) 2-nitrobenzoate with an appropriate N-donor ligand in a methanol-water mixture and allowing the solution to evaporate at room temperature as shown in Scheme 1.

All three complexes have been characterized and investigated by elemental analyses, TGA, spectroscopic (FT-IR, UV/Visible, EPR) and magnetic susceptibility studies, conductance measurements, as well as by single-crystal X-ray crystallography and DFT.

\section{Syntheses}

Synthesis of $\left[\mathrm{Cu}_{2}(2 \text {-nitrobenzoate })_{4}\left(\mathrm{H}_{2} \mathrm{O}\right)_{2}\right] \cdot 2 \mathrm{H}_{2} \mathrm{O}$. Sodium 2-nitrobenzoate was prepared by dissolving $2 \mathrm{~g}(0.012 \mathrm{~mol})$ of

$\mathrm{CuSO}_{4} .5 \mathrm{H}_{2} \mathrm{O}+2 \mathrm{NaOH}+2 \mathrm{RH} \stackrel{\mathrm{H}_{2} \mathrm{O}}{\longrightarrow} 1 / 2\left[\mathrm{Cu}_{2}(\mathrm{R})_{4}\left(\mathrm{H}_{2} \mathrm{O}\right)_{2}\right] \cdot 2 \mathrm{H}_{2} \mathrm{O}+2 \mathrm{NaCl}$

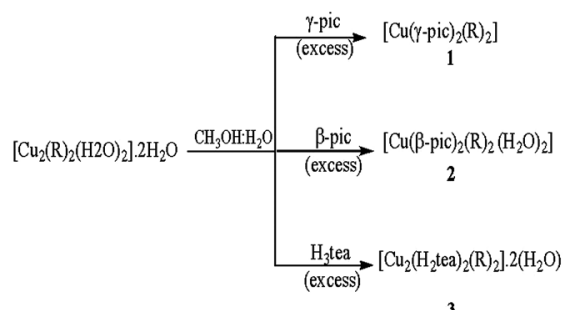

$\mathrm{R}=$ 2-nitrobenzoate

3

Scheme 1 Schematic representation of the synthetic procedure. 2-nitrobenzoic acid and $0.479 \mathrm{~g}(0.012 \mathrm{~mol})$ of sodium hydroxide in a minimum amount of water. $1.490 \mathrm{~g}$ (0.0059 mol) of copper sulphate was dissolved in a minimum amount of water. Upon mixing both solutions at room temperature a green coloured precipitate appeared immediately. The precipitated product was filtered through fine paper, washed with water and dried at room temperature.

Synthesis of $\left.\left[\mathrm{Cu}(\gamma \text {-pic })_{2} \text { (2-nitrobenzoate }\right)_{2}\right]$. 1: $0.05 \mathrm{~g}$ of the green coloured copper(II) 2-nitrobenzoate complex was suspended in a $4: 1$ methanol : water mixture and $\gamma$-pic was added till a clear dark blue coloured solution was obtained. When the solution was allowed to evaporate at room temperature, blue coloured crystals appeared after 3 days. Complex $\mathbf{1}$ is soluble in methanol and insoluble in water and acetone. Complex 1 decomposed at $190{ }^{\circ} \mathrm{C}$. Anal. calcd for $\mathrm{C}_{26} \mathrm{H}_{22} \mathrm{CuN}_{4} \mathrm{O}_{8}$ (\%): C, 53.65; H, 3.78; N, 9.63; Cu, 10.92. Found: C, 52.45; H, 3.66; N, 9.52; Cu, 10.73. IR/ $\mathrm{cm}^{-1}(\mathrm{KBr}): 3565(\mathrm{~m}), 3317(\mathrm{~m}), 3128(\mathrm{~b})$, 3208(m), 3085(w) 1607(s), 1564(ms), 1524(s), 1443(w), 1389(s), 1350(m), 1151(m), 1071(ms), 1034(ms), 977(w), 959(w), 862(m), 835(m), 805(m), 795(m), 785(m) 752(m), 700(m), 648(m), $589(\mathrm{w}), 554(\mathrm{~m}), 493(\mathrm{~ms}), 459(\mathrm{~m})$. UV/Visible $\left(\mathrm{CH}_{3} \mathrm{OH}\right) \lambda_{\max }=$ $732 \mathrm{~nm}\left(\varepsilon_{\max }=94.07 \mathrm{~mol}^{-1} \mathrm{~L} \mathrm{~cm}^{-1}\right)$.

Synthesis of $\left.\left[\mathrm{Cu}(\boldsymbol{\beta} \text {-pic })_{2} \text { (2-nitrobenzoate }\right)_{2}\left(\mathrm{H}_{2} \mathrm{O}\right)_{2}\right] .2$ : Complex 2 was synthesized in a similar manner to complex $\mathbf{1}$ by adding $\beta$-picoline. When the deep blue colored solution was allowed to evaporate at room temperature, blue coloured crystals appeared after 3 days. Complex 2 is soluble in methanol and insoluble in water and acetone. Complex 2 melted at $210{ }^{\circ} \mathrm{C}$. Anal. calcd for $\mathrm{C}_{26} \mathrm{H}_{26} \mathrm{CuN}_{4} \mathrm{O}_{10}$ (\%): C, 50.52; $\mathrm{H}, 4.21 ; \mathrm{N}$, 9.07; $\mathrm{Cu}, 10.28$. Found: $\mathrm{C}$ 50.45; H, 4.16; N, 8.72; Cu, 10.08 . IR/cm ${ }^{-1}$ (KBr): 3524(m), 3371(b), 3235(w), 1593(s), 1567(s), 1530(s), 1481(m), 1393(s), 1367(sh), 1194(w), 1130(w), 1064(w), 862(w), 836(m), 797(m), 744(m), 698(ms), 649(b), 598(w), 513(w), 468(ms). UV/Visible $\left(\mathrm{CH}_{3} \mathrm{OH}\right) \lambda_{\max }=738 \mathrm{~nm}\left(\varepsilon_{\max }=102.5 \mathrm{~mol}^{-1} \mathrm{~L} \mathrm{~cm}^{-1}\right)$.

Synthesis of $\left.\left[\mathrm{Cu}_{2}\left(\mathrm{H}_{2} \text { tea }\right)_{2} \text { (2-nitrobenzoate }\right)_{2}\right] \cdot 2\left(\mathrm{H}_{2} \mathrm{O}\right) .3$ : Complex 3 was synthesized in a similar manner to complexes $\mathbf{1}$ and $\mathbf{2}$ by adding $\mathrm{H}_{3}$ tea. When the deep blue colored solution was allowed to evaporate at room temperature, turquoise blue coloured crystals appeared after four days. The crystals were washed with hexane and vacuum dried. Complex $\mathbf{3}$ is soluble in methanol and insoluble in water and acetone. Complex 3 melted at $135{ }^{\circ} \mathrm{C}$. Anal. calcd for $\mathrm{C}_{26} \mathrm{H}_{36} \mathrm{Cu}_{2} \mathrm{~N}_{4} \mathrm{O}_{14} \cdot 2\left(\mathrm{H}_{2} \mathrm{O}\right)(\%)$ : C, 39.44; H, 5.05; N,7.07; Cu, 16.05. Found: C, 39.25; H, 4.46; N, 6.92; Cu, 15.96. IR/cm ${ }^{-1}$ (KBr): 3418(b), 3225(b), 2944(w), 1601(m), 1566(m), 1548(s), 1537(s), 1450(m), 1385(s), 1171(w), 1137(w), 1084(s), 1053(m), 1024(m), 918(m), 904(m), 813(m), 780(m), 749(w), 705(w), 695(m), 681(w), 648(m), 568(m), 502(w), 466(m). UV/Visible $\left(\mathrm{CH}_{3} \mathrm{OH}\right): \lambda_{\max }=741 \mathrm{~nm}\left(\varepsilon_{\max }=63.5 \mathrm{~mol}^{-1} \mathrm{~L} \mathrm{~cm}^{-1}\right)$.

Details of the TGA and spectroscopic characterization of complexes 1-3 are available in the ESI. $\dagger$

\section{Materials and physical measurements}

Analytical grade reagents were used without any further purification. Carbon, hydrogen and nitrogen were measured micro-analytically using an automatic Perkin Elmer $2400 \mathrm{CHN}$ elemental analyzer and copper was determined gravimetrically. ${ }^{20}$ 
FT-IR spectra were recorded as $\mathrm{KBr}$ pellets using a Perkin Elmer Spectrum RXFT-IR system. The electronic spectrum was recorded in $\mathrm{H}_{2} \mathrm{O}$ using a Hitachi 330 spectrophotometer. The thermogravimetric analysis (TGA) was conducted using an SDT Q600 instrument. The samples contained in the alumina pan were heated from $25{ }^{\circ} \mathrm{C}$ to $1000{ }^{\circ} \mathrm{C}$ at a constant rate of $10{ }^{\circ} \mathrm{C} \mathrm{min}{ }^{-1}$ in a nitrogen environment with a flux (flow rate) of $10 \mathrm{~mL} \mathrm{~min}^{-1}$. Conductance measurements were performed using a Pico Conductivity Meter (Model CNO4091201, Lab India) in aqueous medium at $25{ }^{\circ} \mathrm{C}$ by using double distilled water. Magnetic measurements for 1 and 2 at room temperature were carried out using the Gouy's method with following specifications: pole face diameter: $10.2 \mathrm{~cm}$; pole gap: $4.0 \mathrm{~cm}$; current: 7.0 \& magnetic induction: 0.6 Tesla. Magnetic susceptibility measurements for 3 over the temperature range $1.8-300 \mathrm{~K}$ were performed at a magnetic field of $0.5 \mathrm{~T}$ using a Quantum Design SQUID MPMSXL-5 magnetometer. Correction for the sample holder as well as the diamagnetic correction $\chi_{\mathrm{D}}$ which was estimated from the Pascal constants were applied. ${ }^{21}$

X-band EPR High-field and high-frequency EPR spectra at temperatures ranging from $c a$. $6 \mathrm{~K}$ to $290 \mathrm{~K}$ were recorded for 3 on a home-built spectrometer at the EMR facility of the NHMFL. ${ }^{22}$

The instrument is a transmission-type device in which microwaves are propagated in cylindrical lightpipes. The microwaves were generated by a phase-locked Virginia Diodes source generating a frequency of $13 \pm 1 \mathrm{GHz}$ and producing its harmonics of which the 2nd, 4th, 6th, 8th, 16th, 24th and 32nd were available. A superconducting magnet (Oxford Instruments) capable of reaching a field of $17 \mathrm{~T}$ was employed. The EPR spectra at X- and Q-bands were measured using a Bruker Elexsys E500 spectrometer equipped with a NMR teslameter and frequency counters. The simulations of the experimental spectra were performed using computer programs employing full diagonalization of the spin Hamiltonian matrix, written by one of us.

\section{Crystallography}

The crystallographic data for 1, 2, and 3 were collected using a Nonius Kappa CCD diffractometer at room temperature using graphite-monochromated $\operatorname{MoK} \alpha$ radiation $(\lambda=0.71073 \AA)$. Data sets were integrated using the Denzo-SMN package ${ }^{23}$ and corrected for Lorentz-polarization and absorption effects. ${ }^{24}$ The structures were solved by direct methods (SIR97) ${ }^{25}$ and refined by full-matrix least-squares methods with all nonhydrogen atoms being anisotropic. As for hydrogen atoms, those belonging to methyl groups in $\mathbf{1}$ and all the $\mathrm{C}-\mathrm{H}$ in $\mathbf{2}$ and 3 were included on calculated positions, riding on their carrier atoms; the others were located in the difference-Fourier map and refined isotropically. All other calculations were performed using SHELXL-97 ${ }^{26}$ implemented in the WINGX system of programs. ${ }^{27}$ The experimental details are reported in Table 1.

\section{Quantum mechanical calculations}

The 'in vacuum' fully optimized geometries of $\left[\mathrm{Cu}(\gamma-\mathrm{pic})_{2}\right.$ (2-nitrobenzoate $\left.)_{2}\right] \quad(1)$ and $\left[\mathrm{Cu}(\beta \text {-pic })_{2}\right.$ (2-nitrobenzoate). $\left.2\left(\mathrm{H}_{2} \mathrm{O}\right)_{2}\right](2)$ complexes have been obtained by density functional theory (DFT) calculations carried out at the B3LYP/6-31G(d,p) level of theory using the Firefly system of programs. ${ }^{28,29}$

ORCA software ${ }^{30}$ was used to perform the "broken symmetry" DFT calculations of exchange parameters $J$ for 3. All atoms were retained at the positions determined by the X-ray structures. The "broken symmetry" procedure applied to a dimeric copper(II) complex first performs a Self-Consistent Field (SCF) calculation for a high-spin molecule (HS) with the spin equal to 1 . In the next stage, another SCF calculation is performed taking the spin on one $\mathrm{Cu}$ atom 'up' and 'down' on another, which is referred to as the broken symmetry state (BS). Finally, the magnitude of $J$ (for the spin Hamiltonian 1) is evaluated as $J=2\left(E_{\mathrm{HS}}-E_{\mathrm{BS}}\right) /\left(\left\langle S^{2}\right\rangle_{\mathrm{HS}}-\left\langle S^{2}\right\rangle_{\mathrm{BS}}\right)$, where $E$ are the energies and $\langle S\rangle^{2}$ are the expectation values of the spin-squared operator in the HS and BS states.

Ahlrichs-type basis set TZVPP ${ }^{31}$ for copper(II) and all coordinated atoms, and $\mathrm{VDZ}^{31 a}$ for other atoms were used, combined with the $\mathrm{B} \mathrm{LYP}^{32}$ functional. Ahlrichs polarisation functions from basis $\mathrm{H}-\mathrm{Kr} \mathrm{R}$ and auxiliary bases from the TurboMole library were also used. ${ }^{31 b}$

Table 1 Experimental details

\begin{tabular}{|c|c|c|c|}
\hline & 1 & 2 & 3 \\
\hline Chemical formula & $\mathrm{C}_{26} \mathrm{H}_{22} \mathrm{CuN}_{4} \mathrm{O}_{8}$ & $\mathrm{C}_{26} \mathrm{H}_{26} \mathrm{CuN}_{4} \mathrm{O}_{10}$ & $\mathrm{C}_{26} \mathrm{H}_{36} \mathrm{Cu}_{2} \mathrm{~N}_{4} \mathrm{O}_{14} \cdot 2\left(\mathrm{H}_{2} \mathrm{O}\right)$ \\
\hline$M_{\mathrm{r}}$ & 582.02 & 618.05 & 791.70 \\
\hline Crystal system, space group & Monoclinic, $P 2_{1} / c$ & Monoclinic, $P 2_{1} / c$ & Monoclinic, $P 2_{1} / c$ \\
\hline$a, b, c(\AA)$ & $\begin{array}{l}7.8506(1), 21.8740(4), \\
8.1508(2)\end{array}$ & $\begin{array}{l}8.0020(2), 12.2397(3), \\
14.5180(3)\end{array}$ & $\begin{array}{l}7.6633(2), 27.2585(7) \\
8.5840(2)\end{array}$ \\
\hline$\beta\left(^{\circ}\right)$ & $103.0120(6)$ & $105.1790(11)$ & $117.5840(11)$ \\
\hline$Z$ & 2 & 2 & 2 \\
\hline$V\left(\AA^{3}\right)$ & $1363.75(5)$ & $1372.32(6)$ & $1589.29(7)$ \\
\hline$\mu\left(\mathrm{mm}^{-1}\right)$ & 0.86 & 0.86 & 1.42 \\
\hline Crystal size (mm) & $0.52 \times 0.47 \times 0.17$ & $0.26 \times 0.20 \times 0.18$ & $0.55 \times 0.26 \times 0.12$ \\
\hline $\begin{array}{l}\text { No. of measured, independent and observed } \\
{[I>2 \sigma(I)] \text { reflections }}\end{array}$ & $16268,3883,3325$ & $16455,3294,2519$ & $6658,3325,2884$ \\
\hline$R_{\text {int }}$ & 0.034 & 0.039 & 0.056 \\
\hline$R\left[F^{2}>2 \sigma\left(F^{2}\right)\right], \mathrm{w} R\left(F^{2}\right), S$ & $0.038,0.115,1.08$ & $0.043,0.136,1.02$ & $0.045,0.142,0.99$ \\
\hline No. of reflections & 3883 & 3294 & 3325 \\
\hline No. of parameters & 211 & 196 & 249 \\
\hline$\Delta \rho_{\max }, \Delta \rho_{\min }\left(\mathrm{e} \AA^{-3}\right)$ & $0.31,-0.44$ & $0.32,-0.61$ & $0.54,-1.03$ \\
\hline
\end{tabular}




\section{Results and discussion}

The composition of 1, 2 and $\mathbf{3}$ was established by elemental analysis. The mode of coordination of the carboxylate ligand in these complexes was indicated by IR spectral criterion $\Delta v=v_{\text {carboxylato(asym) }}-v_{\text {carboxylato(sym) }}$ as reported in literature. ${ }^{33,34}$

\section{Molecular geometry and coordination}

To determine the structures unambiguously and to analyse the packing modes, single X-ray crystal structure determination of complexes 1, 2 and 3 was undertaken. Fig. 1-3 report the ORTEPIII diagrams for 1-3, respectively.

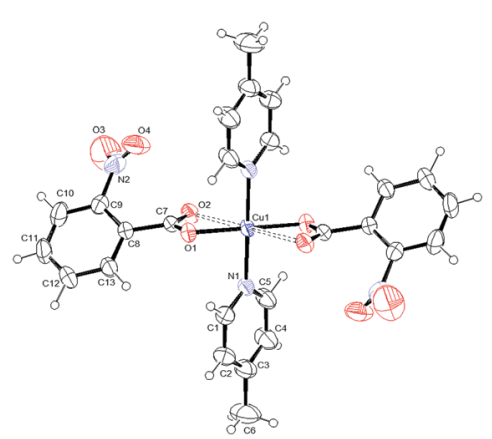

Fig. 1 ORTEPIII view and the atom numbering scheme for 1 . Thermal ellipsoids are drawn at the $50 \%$ probability level. Contact distances are shown as dashed lines.

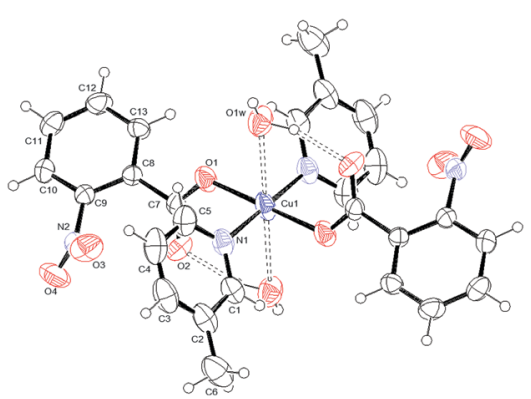

Fig. 2 ORTEPIII view and the atom numbering scheme for 2 . Thermal ellipsoids are drawn at the $40 \%$ probability level. Contact distances and hydrogen bonds are shown as dashed lines.

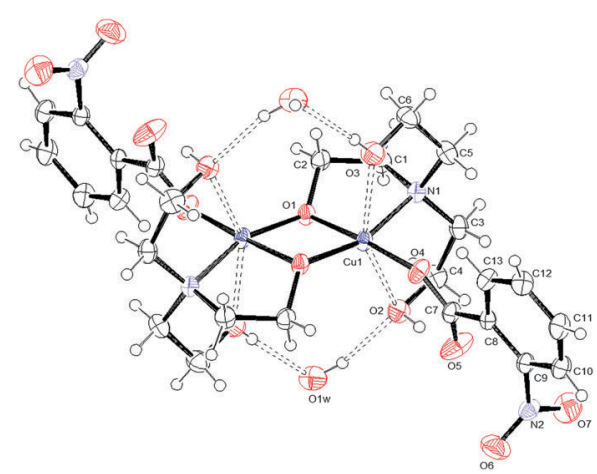

Fig. 3 ORTEPIII view and the atom numbering scheme for 3 . Thermal ellipsoids are drawn at the $40 \%$ probability level. Contact distances and hydrogen bonds are shown as dashed lines.
Table 2 Selected geometric parameters $\left(\AA \AA{ }^{\circ}\right)$

\begin{tabular}{|c|c|c|c|}
\hline \multicolumn{4}{|l|}{1} \\
\hline Cu1-N1 & $2.005(1)$ & $\mathrm{Cu} 1 \ldots \mathrm{O} 2$ & $2.518(1)$ \\
\hline Cu1-O1 & $1.987(1)$ & & \\
\hline N1-Cu1-O1 & $89.24(5)$ & $\mathrm{N} 1-\mathrm{Cu} 1-\mathrm{O} 2$ & $88.19(5)$ \\
\hline \multicolumn{4}{|c|}{$\mathrm{Cu} \cdots \mathrm{Cu}$ contacts } \\
\hline $\mathrm{Cu} \cdots \mathrm{Cu}$ & 7.8506(1) & $8.1508(2)$ & \\
\hline \multicolumn{4}{|l|}{2} \\
\hline Cu1-N1 & $1.997(2)$ & Cu1 $\cdots$ O1W & $2.739(2)$ \\
\hline $\mathrm{Cu} 1-\mathrm{O} 1$ & $1.971(2)$ & & \\
\hline N1-Cu1-O1 & $91.02(7)$ & N1-Cu1-O1w & $91.10(8)$ \\
\hline O1-Cu1-O1w & $96.00(7)$ & & \\
\hline \multicolumn{4}{|c|}{$\mathrm{Cu} . . \mathrm{Cu}$ contacts } \\
\hline $\mathrm{Cu} \ldots \mathrm{Cu}$ & $8.0020(2)$ & 9.4945(1) & \\
\hline \multicolumn{4}{|l|}{3} \\
\hline $\mathrm{Cu} 1-\mathrm{O} 1$ & $1.946(2)$ & $\mathrm{Cu} 1 \cdots \mathrm{O} 3$ & $2.478(2)$ \\
\hline Cu1-N1 & $2.042(2)$ & $\mathrm{Cu} 1-\mathrm{O} 4$ & $1.966(3)$ \\
\hline $\mathrm{Cu} 1 \cdots \mathrm{O} 2$ & $2.576(2)$ & $\mathrm{Cu} \cdots \mathrm{Cu}^{a}$ & $2.9187(4)$ \\
\hline $\mathrm{Cu} 1-\mathrm{O} 1^{a}$ & $1.934(2)$ & & \\
\hline O1-Cu1-N1 & $85.00(9)$ & N1-Cu1-O3 & 76.3(1) \\
\hline $\mathrm{O} 1-\mathrm{Cu} 1-\mathrm{O} 2$ & $90.59(9)$ & N1-Cu1-O4 & $98.70(9)$ \\
\hline O1-Cu1-O3 & $97.2(1)$ & $\mathrm{O} 2-\mathrm{Cu} 1-\mathrm{O} 4$ & $88.83(9)$ \\
\hline N1-Cu1-O2 & $78.40(9)$ & O3-Cu1-O4 & $85.0(1)$ \\
\hline $\mathrm{O} 1-\mathrm{Cu} 1-\mathrm{O} 1^{a}$ & $82.46(9)$ & $\mathrm{Cu} 1-\mathrm{O} 1-\mathrm{Cu} 1^{a}$ & $97.5(1)$ \\
\hline
\end{tabular}

Relevant geometrical parameters are reported in Table 2. In $\mathbf{1}$ and $\mathbf{2}$, the $\mathrm{Cu}$ atom lies on an inversion center, while in $\mathbf{3}$ a symmetry center is positioned just in the middle of the binuclear complex. In both $\mathbf{1}$ and $\mathbf{2}$ complexes, the $\mathrm{Cu}$ atom is linked to two picoline and two monodentate benzoate ligands, bonded via $\mathrm{O} 1$. In addition, it is involved in two further second-order interactions, giving a final $(4+2)$ coordination: in 1 the carboxylic oxygens (O2) are at a $\mathrm{Cu}-\mathrm{O}$ distance of $2.518(1) \AA$, while in $\mathbf{2}$ two centrosymmetrically related water molecules are at a distance of 2.739(2) $\AA$ (Table 2). The angles formed by the $\mathrm{O} 2-\mathrm{Cu} 1$ and $\mathrm{O} 1 \mathrm{w}-\mathrm{Cu} 1$ lines with the normal to mean basal planes measure $32.60(4)$ and $6.08(7)^{\circ}$ in 1 and 2, respectively. Complex 3 is dimeric with the de-protonated oxygen atom of the $\mathrm{H}_{2}$ tea ligand forming a bridge between two centrosymmetrically related $\mathrm{Cu}(\mathrm{II})$ atoms. The coordination geometry of 3 can be described, in analogy with those reported in the literature for analogous $\mathrm{Cu}$ (II) benzoate, ${ }^{35}$ 3-chlorobenzoate ${ }^{36}$ and 4-methylbenzoate ${ }^{37}$ complexes, as distorted tetragonal bipyramidal (or highly distorted octahedral), with each $\mathrm{H}_{2}$ tea molecule acting as a tetradentate ligand or as square-planar with two additional interactions like in $\mathbf{1}$ and 2 .

Actually, the equatorial plane in $\mathbf{3}$ is defined by one carboxylate oxygen atom of 2-nitrobenzoate, two bridging alkoxo oxygen atoms and one nitrogen while $\mathrm{O} 2$ and $\mathrm{O} 3$ atoms of $\mathrm{H}_{2}$ tea are located at much longer distances (Table 2); the $\mathrm{Cu}$ atom is displaced by $0.023 \AA$ from the least-square plane passing through (O1, N1, O4) and the angles formed by $\mathrm{Cu} 1-\mathrm{O} 2$ and Cu1-O3 lines with the normal to this plane are 16.44(9) and $11.19(8)^{\circ}$, respectively. For each dimeric moiety, two water molecules of crystallization are present in the crystal.

The $\mathrm{Cu}-\mathrm{N}$ distances are similar in all the three complexes and do not show any significant discrepancy from structural parameters of related $\mathrm{Cu}$ compounds. The $\mathrm{Cu}-\mathrm{O}$ distances 


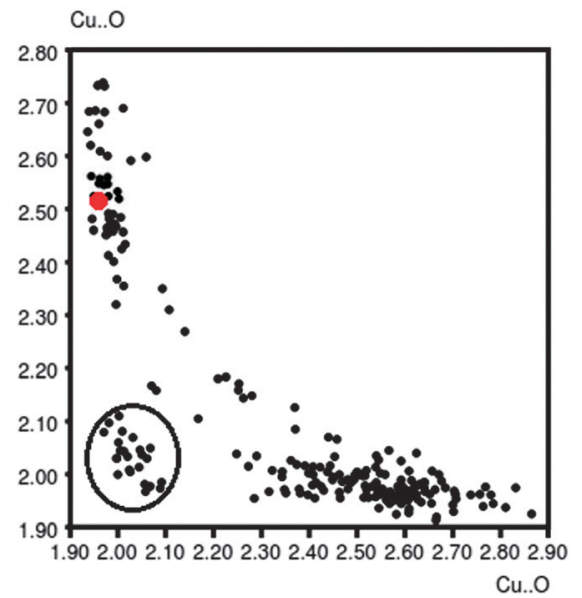

Fig. 4 Intercorrelation between the $\mathrm{Cu}-\mathrm{O}$ distances in $\mathrm{Cu}(\mathrm{II})$ benzoate complexes. Data for compound 1 are reported as red points.

display a wide range of values, from 1.934(2) $\AA$ (oxo-bridge, complex 3) to 2.739(2) $\AA$ (water molecule, complex 2), that can be more appropriately considered as a contact distance. The histogram of the $\mathrm{Cu}-\mathrm{O}$ (benzoate) distances, obtained from a search on the CSD database (278 hits) considering both the oxygens linked to the metal, is clearly bimodal showing two distinct bond length distributions around 2.0 and $2.6 \AA$, respectively, in perfect agreement with the structural data of 1 and 3. Moreover, Fig. 4, obtained by the same CSD search, suggests that these two distances are intercorrelated; if one increases, the other decreases. Geometrical data of complex 1 (red point) are perfectly in line with the others. The points enclosed in a circle, which do not follow the curve trend, refer to particular structures: of polymeric type, with huge ligands, or having $\mathrm{Cl}^{-}$anions as ligands.

As far as the binuclear complex 3 is concerned, a comparison with the similar $\mathrm{Cu}-\mathrm{H}_{2}$ tea complexes above mentioned ${ }^{35-37}$ shows that the molecular arrangement around the $\mathrm{Cu}$ atoms and the geometrical parameters are strictly comparable in all of them; benzoates are acting as monodentate ligands, with the oxygen of anionic $\mathrm{H}_{2}$ tea bridging two metals, and one $\mathrm{OH}$ group of the $\mathrm{H}_{2}$ tea being involved in an intramolecular hydrogen bond with the free benzoate oxygen. Moreover, two cocrystallized water molecules for each binuclear complex are always present connecting different molecules in exactly the same way as in complex 3 (vide infra), suggesting that in these structures, the presence of water is essential for the robustness of the crystalline framework.

It is interesting to note that complexes $\mathbf{1}$ and $\mathbf{2}$ present a different $\mathrm{Cu}$ environment in spite of having almost identical ligands ( $p$-methyl and $o$-methyl pyridine, respectively). In order to explore whether the choice of different picoline molecules can affect the possibility of water inclusion in the first or the second coordination sphere, the equilibrium geometry of both complexes has been obtained by DFT calculations starting from the same initial point, i.e. by adding two $\mathrm{Cu}$-coordinated water molecules to the picoline/benzoate skeleton at a distance of $2.40 \AA$ or using an initial geometry with no coordinated water molecules.

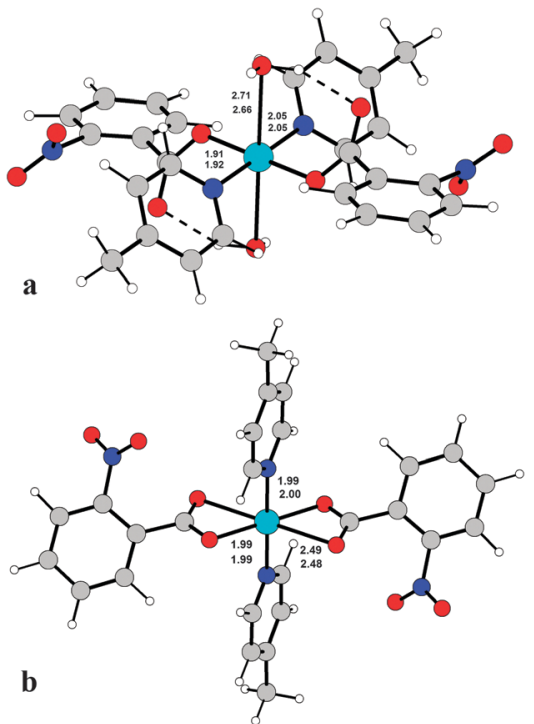

Fig. 5 DFT equilibrium geometries of complex 2 (a) in diaquo-form and (b) without coordinated water molecules. Relevant distances are shown together with the corresponding calculated bond lengths for complex 1 (reported underneath).

The results are reported in Fig. 5. For the diaquo complexes, the $\mathrm{Cu}-\mathrm{O}, \mathrm{Cu}-\mathrm{N}$ distances are strictly comparable and the energies of the calculated molecules are practically identical: the $\gamma$-picoline complex is more stable than the $\beta$-picoline one by $0.36 \mathrm{kcal} \mathrm{mol}^{-1}$. The same results have been obtained for complexes without water, but in this case the $\gamma$-picoline compound is more stable by $2.13 \mathrm{kcal} \mathrm{mol}^{-1}$; this extra-stability is however not sufficient to explain the different coordination of the two compounds, which probably depends mostly on the solvent used (or in general on the crystallization conditions).

As mentioned at the outset, one of our objectives was to delineate the variation/change in the conformation of the carboxylate ligand upon the addition of three different $\mathrm{N}$-donor ligands, two rigid (picolines) and one flexible $\left(\mathrm{H}_{3} t e a\right)$. Indeed, as anticipated, the $-\mathrm{NO}_{2}$ moiety is out of plane from the aromatic ring in all three, but the extent of variation is quite large, ranging from $42.4(3), 53.9(3)$ and $81.6(4)^{\circ}$ for $\mathbf{1}, 2$ and 3 respectively (note that this variation is highest with the most flexible $\mathrm{N}$-donor ligand $\mathrm{H}_{3}$ tea).

In an analogous manner, the $-\mathrm{COO}^{-}$moiety also gets rotated with respect to the aromatic plane, the highest rotation being observed in 1 and $2\left(42.6(2)\right.$ and $\left.42.3(3)^{\circ}\right)$ and almost in-plane of the aromatic ring in $3\left(5.2(2)^{\circ}\right)$. Here also that distinction prevails; the rigid $\mathrm{N}$-donor ligands are similar in behavior and the flexible one shows considerable deviation. It is clear that each of these structures would try to maximize the resonance energy by keeping both $-\mathrm{NO}_{2}$ and - $\mathrm{COO}$ groups in plane with the aromatic ring, but the opposing steric repulsion needs to be compensated by allowing them to move away from the plane to the extent that the lattice energy is minimum (most stable arrangement). Thus, in the most flexible deprotonated ligand $\mathrm{H}_{2}$ tea (3) $-\mathrm{COO}^{-}$is only few degrees away from the plane, but at the same time the $-\mathrm{NO}_{2}$ is almost orthogonal. 


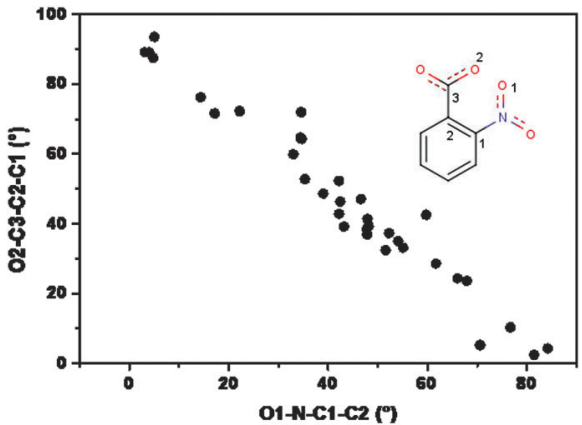

Fig. 6 Scatter plot of the out of plane angles for $\mathrm{NO}_{2}$ and $\mathrm{COO}^{-}$groups in Cu(2-nitrobenzoate) complexes.

In the rigid $\mathrm{N}$-donors $\mathbf{1}$ and $\mathbf{2}$ the situation is in between, both the groups deviate to the extent of some $45^{\circ}$. These findings are supported by the survey of the conformation of the nitrobenzoate moiety in $\mathrm{Cu}$ complexes with $\mathrm{N}$-donor ligands already present in literature. 21 structures of this type were found in the CSD; for each of them the $\mathrm{NO}_{2}{ }^{-}$and $\mathrm{COO}^{-}$out-of-plane was evaluated through the measure of the torsion angles $\mathrm{O} 1-\mathrm{N}-\mathrm{C} 1-\mathrm{C} 2$ and O2-C3-C2-C1 (see Fig. 6). As shown in the plot, the two angles are strongly intercorrelated in the same way as found for the present complexes; the $\mathrm{COO}^{-}$group is rarely coplanar with the phenyl moiety, and this happens when both the oxygens are 'busy' in covalent or strong H-bonding interactions within a same molecular complex, in which the $\mathrm{Cu}$ atom is linked to small or highly conformationally adaptable N-donor ligands.

This observation becomes interesting when we consider the mode of coordination in 1, 2 and 3 . In 1, the carboxylate group is monodentate but the second oxygen is still interacting with the $\mathrm{Cu}$ atom, (Table 2) whereas in 2 one of the $\mathrm{Cu}-\mathrm{O}$ distance becomes so large (3.185(2) A) that the coordination is obviously monodentate and it is much higher yet in 3 (3.378(3) Å). That is, the nature of the N-donor ligand definitely exerts influence on the coordination mode and this in turn affects the structure and the packing architecture of the crystallized complex.

\section{Packing}

The hydrogen bonding structural parameters for the three complexes are reported in Table 3 . In $\mathbf{1}$, the presence of a number of good hydrogen bonding acceptors but a lack of good hydrogen bonding donors allows only the formation of $\mathrm{C}-\mathrm{H} \cdots \mathrm{O}$ bonds. The $\mathrm{C}-\mathrm{H} \cdots \mathrm{O} 1$ contact on the two sides of the molecule generates ribbons linking the complexes along the $c$ direction. These ribbons are in turn connected along the $b$ direction through $\mathrm{C}-\mathrm{H} \cdots \mathrm{O} 2$ interactions. Conversely, in 2 and 3 the presence of water molecules or hydroxyl groups leads to strong $\mathrm{O}-\mathrm{H} \cdots \mathrm{O}$ interactions, both intermolecular and intramolecular. In 2, the coordinated water molecules, besides being involved in intramolecular interactions, act as H-bond donors towards the $\mathrm{O} 2$ atoms of an adjacent molecule, giving rise to the $\mathrm{R}_{2}^{2}(12)$ ring as shown in Fig. 7 .

The resulting overall packing is made of parallel ribbons running along the $a$ direction. In $\mathbf{3}$, the interaction network is
Table 3 Hydrogen bonding parameters; $D=$ donor, $A=\operatorname{acceptor}\left(\AA \AA{ }^{\circ}\right)$

\begin{tabular}{|c|c|c|c|c|}
\hline $\mathrm{D}-\mathrm{H} \cdots \mathrm{A}$ & $\mathrm{D}-\mathrm{H}$ & $\mathrm{D} \cdots \mathrm{A}$ & $\mathrm{H} \cdots \mathrm{A}$ & Angle \\
\hline \multicolumn{5}{|l|}{ Complex 1} \\
\hline $\mathrm{C} 2-\mathrm{H} 2 \cdots \mathrm{O} 2^{a}$ & $0.95(2)$ & $3.268(2)$ & $2.36(3)$ & $160(2)$ \\
\hline $\mathrm{C} 4-\mathrm{H} 6 \cdots \mathrm{O}^{b}$ & $0.90(3)$ & $3.451(2)$ & $2.56(3)$ & $168(2)$ \\
\hline \multicolumn{5}{|l|}{ Complex 2} \\
\hline $\mathrm{O} 1 \mathrm{~W}-\mathrm{H} 2 \mathrm{~W} \cdots \mathrm{O} 2^{c}$ & $0.93(4)$ & $2.728(3)$ & $1.83(4)$ & $163(4)$ \\
\hline $\mathrm{O} 1 \mathrm{~W}-\mathrm{H} 1 \mathrm{~W} \cdots \mathrm{O} 2^{d}$ & $0.89(4)$ & $2.892(3)$ & $2.06(4)$ & $154(4)$ \\
\hline $\mathrm{C} 3-\mathrm{H} 3 \cdots \mathrm{O} 1 \mathrm{~W}^{e}$ & 0.93 & $3.426(4)$ & 2.53 & 161 \\
\hline $\mathrm{C} 6-\mathrm{H} 62 \cdots \mathrm{O}^{f}$ & 0.96 & $3.440(5)$ & 2.56 & 151 \\
\hline $\mathrm{C} 12-\mathrm{H} 12 \cdots \mathrm{O} 2^{g}$ & 0.93 & $3.397(3)$ & 2.49 & 163 \\
\hline \multicolumn{5}{|l|}{ Complex 3} \\
\hline $\mathrm{O} 2-\mathrm{H} 2 \cdots \mathrm{O} 5$ & $0.85(5)$ & $2.631(4)$ & $1.80(5)$ & $165(4)$ \\
\hline $\mathrm{O} 1 \mathrm{~W}-\mathrm{H} 2 \mathrm{~W} \cdots \mathrm{O} 2$ & $0.84(5)$ & $2.870(4)$ & $2.05(6)$ & $164(5)$ \\
\hline $\mathrm{O} 1 \mathrm{~W}-\mathrm{H} 1 \mathrm{~W} \cdots \mathrm{O} 1^{h}$ & $0.82(7)$ & $2.997(4)$ & $2.28(7)$ & $146(6)$ \\
\hline $\mathrm{O} 3-\mathrm{H} 3 \cdots \mathrm{O} 1 \mathrm{~W}^{i}$ & $0.71(6)$ & $2.711(4)$ & $2.01(6)$ & $171(6)$ \\
\hline $\mathrm{C} 1-\mathrm{H} 1 \mathrm{~B} \cdots \mathrm{O} 1 \mathrm{~W}^{j}$ & 0.97 & $3.397(4)$ & 2.61 & 138 \\
\hline
\end{tabular}

${ }^{a} x-1, y, z .{ }^{b} x, y, z+1 .{ }^{c} 1-x,-y,-z .{ }^{d} x+1, y, z .{ }^{e} x, 1 / 2-y, z+1 / 2$. ${ }^{f} 1-x, y-1 / 2,1 / 2-z \cdot{ }^{g} x, 1 / 2-y, z-1 / 2 .{ }^{h}-x,-y,-z \cdot{ }^{i} 1-x,-y$, $-z .^{j} x+1, y, z+1$.

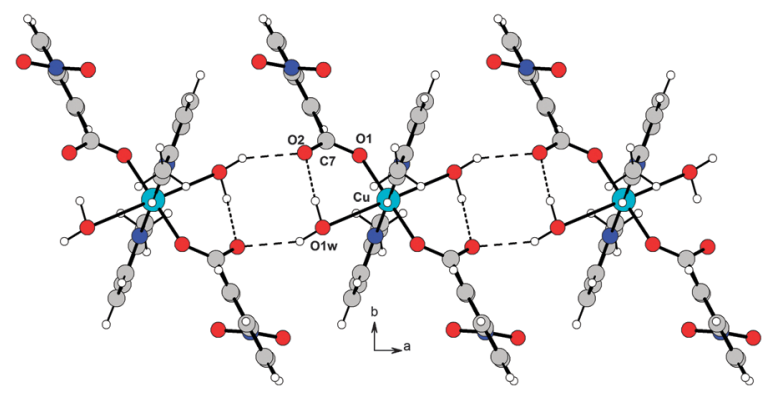

Fig. $7 \mathrm{O}-\mathrm{H} \ldots \mathrm{O}$ hydrogen bond arrangement in 2. Intermolecular and intramolecular hydrogen bonds are shown as dashed and dotted lines, respectively.

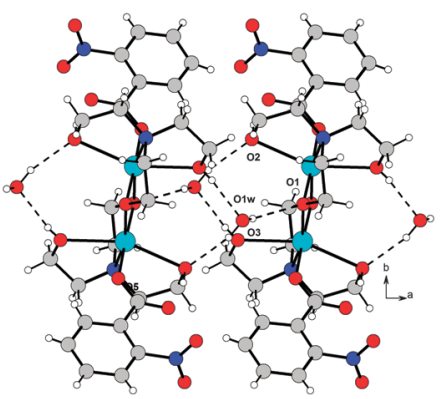

Fig. $8 \mathrm{O}-\mathrm{H}$... O hydrogen bond arrangement in 3. Intermolecular hydrogen bonds are shown as dashed lines. For the sake of clarity, intramolecular $\mathrm{O}-\mathrm{H} \ldots \mathrm{O}$ interactions are not shown.

somewhat similar but more complex than 2 due to the presence of a large number of hydrogen bond donor and acceptor groups. Water molecules of crystallization act as linkers by bridging the adjacent molecules; they behave as hydrogen bond donors towards $\mathrm{O} 1$ and $\mathrm{O} 2$ atoms and as acceptors to the $\mathrm{O} 3$ atom. This results in formation of molecular ribbons running along the $a$ direction (Fig. 8). In both structures the crystal lattice is further stabilized by weak $\mathrm{C}-\mathrm{H} \cdots \mathrm{O}$ interactions. 


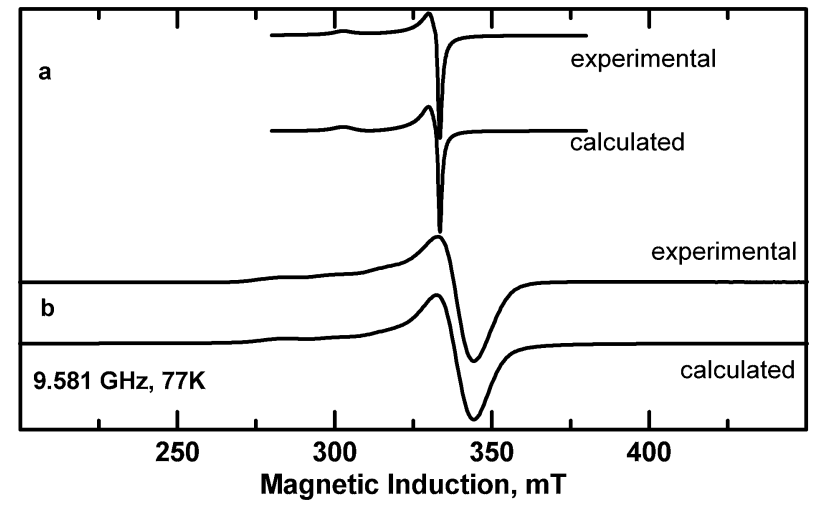

Fig. $9 \mathrm{X}$-band EPR spectra of powdered complexes (a) 1 and (b) 2 at $77 \mathrm{~K}$ (experimental and calculated with the parameters given in the text).

\section{Magnetic and EPR measurements}

Magnetic moments higher than the spin-only value of 1.73 are observed in copper(II) complexes $\left(3 \mathrm{~d}^{9}\right)$, due to spin-orbit coupling. Monomeric copper(II) complexes generally show magnetic moments in the range 1.75 to $2.2 \mu_{\mathrm{B}}$ at room temperature. The EPR spectra of the powdered complexes with $g_{x}=2.056$, $g_{y}=2.066$ and $g_{z}=2.258$ parameters for 1 (Fig. 9a) and $g_{x}=2.057$, $g_{y}=2.057$ and $g_{z}=2.262$ for 2 (Fig. 9b) are typical for axial symmetry of $\mathrm{Cu}$ (II) coordination polyhedron (with a very weak rhombic distortion) for $\mathbf{1}$ and axial symmetry for 2 . The $g$ parameter values for 1 and 2 correspond to the $\mathrm{d}_{x^{2}-y^{2}}$ orbital of the unpaired electron ground state and are characteristic of the $\mathrm{N} 2 \mathrm{O} 2$ donor set provided by the ligands in the $x y \mathrm{Cu}(\mathrm{II})$ plane. The low field "parallel" part of the spectrum for 2 exhibits signals due to hyperfine interaction between unpaired electrons and copper nucleus (nuclear spin $I=3 / 2$ ) with $A_{\|}=169 \times 10^{-4} \mathrm{~cm}^{-1}$ (Fig. 9b). It is a rare case when the hyperfine splitting is resolved in a powder EPR spectrum of a $\mathrm{Cu}$ (II) complex suggesting a greater isolation of $\mathrm{Cu}$ (II) centers than in $\mathbf{1}$ due to water molecules at axial positions which are involved in hydrogen bonds with carboxyl groups. The $\mathrm{Cu}-\mathrm{Cu}$ distances are in fact greater in $\mathbf{2}$ than in $\mathbf{1}$ (Table 2).

\section{Magnetic susceptibility and EPR spectra of 3}

The temperature dependence of the effective magnetic moment of 3 is shown in Fig. 10.

The moment is seen to increase with decreasing temperature, to reach a plateau between 25 and $4.5 \mathrm{~K}$, followed by a decrease at the lowest temperatures. This is a characteristic pattern of a ferromagnetically coupled dimer. The exchange interactions, responsible for that behavior, can be described by the classical Heisenberg-Dirac-VanVleck Hamiltonian

$$
\hat{\mathbf{H}}=J \hat{\mathbf{S}}_{1} \hat{\mathbf{S}}_{2}
$$

where $\hat{\mathbf{S}}_{1}$ and $\hat{\mathbf{S}}_{2}$ are the spin operators of the interacting ions, and $J$ is the exchange integral, negative for the ferromagnetic interactions in our notation. The exchange interactions lead to the spin triplet state $(S=1)$ and spin singlet state $(S=0)$. The energy difference between these states equals $J$.

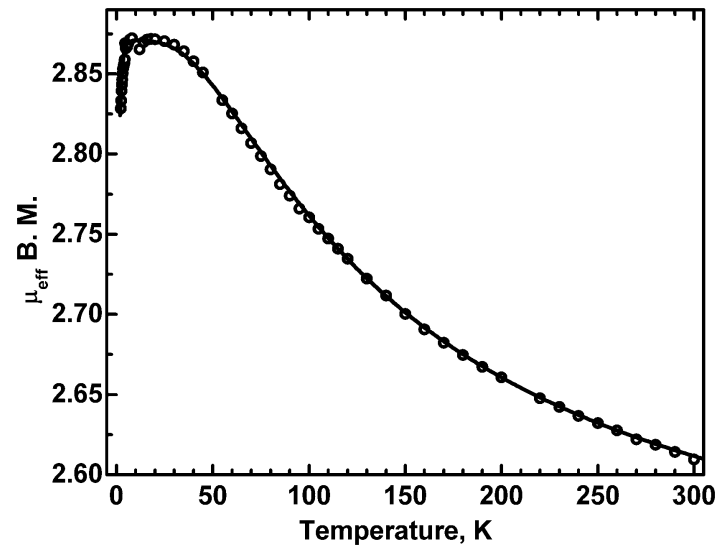

Fig. 10 The effective magnetic moment of 3 as a function of temperature. Dots: experimental, solid line - calculated with $\mathrm{J}=-100 \mathrm{~cm}^{-1}$ (see the text).

The magnetic susceptibility per mole of a dimeric copper(II) complex can be calculated from

$$
\chi_{\mathrm{d}}=\frac{N \mu_{\mathrm{B}}^{2} g^{2}}{3 k T} \frac{6 \exp (-J / k T)}{1+3 \exp (-J / k T)}
$$

However, this equation cannot reproduce the magnetic moment drop at the lowest temperatures. That drop is caused by the combined Zeeman and zero-field splitting of the triplet state being comparable to the thermal energy $k T$. To account for this, terms expressing those interactions must be added to the HDVV Hamiltonian:

$$
\begin{aligned}
\hat{\mathbf{H}}= & J \hat{\mathbf{S}}_{1} \hat{\mathbf{S}}_{2}+D_{12}\left\{\hat{\mathbf{S}}_{z 1} \hat{\mathbf{S}}_{z 2}-\hat{\mathbf{S}}_{1} \cdot \hat{\mathbf{S}}_{2} / 3\right\}+E_{12}\left(\hat{\mathbf{S}}_{x 1} \hat{\mathbf{S}}_{x 2}-\hat{\mathbf{S}}_{y 1} \hat{\mathbf{S}}_{y 2}\right) \\
& +\mu_{\mathrm{B}} B\left\{\boldsymbol{g}_{1}\right\} \hat{\mathbf{S}}_{1}+\mu_{\mathrm{B}} B\left\{\boldsymbol{g}_{2}\right\} \hat{\mathbf{S}}_{2}
\end{aligned}
$$

The spin Hamiltonian matrix was diagonalised to find the energy levels and the magnetic susceptibility per mole of the dimer was calculated from

$$
\chi_{\mathrm{d}}=-\frac{N}{B} \frac{\sum_{i} \frac{\partial E_{i}}{\partial B} \exp \left(-E_{i} / k T\right)}{\sum_{i} \exp \left(-E_{i} / k T\right)}
$$

The derivatives $\partial E_{i} / \partial B$ can be evaluated numerically by calculating the energy levels slightly below and slightly above ( \pm 5 Gauss) the operational magnetic field of a SQUID magnetometer ( $5000 \mathrm{G}$ in our case). The $D$ and $E$ parameters have been determined from the EPR spectra (see below) and were not allowed to vary in the fitting of the magnetic data. The complex is strongly hygroscopic resulting in some uncertainty of the molar mass at the time of the magnetic measurement. To account for the observed slightly too low magnetic susceptibility, the $g$ values were allowed to vary, but the ratio of $g_{z}$ to $g_{x}$ and $g_{y}$ was fixed as observed in EPR. The fitting procedure resulted in $J=-100 \mathrm{~cm}^{-1}$, representing relatively strong ferromagnetic interactions. This $J$ value is slightly greater than that observed for an analogous dimer derived from benzoic acid. ${ }^{35}$ It is known since $1976^{38}$ that in bis(hydroxo) and bis(alkoxo) bridged copper(II) complexes a relationship exists 

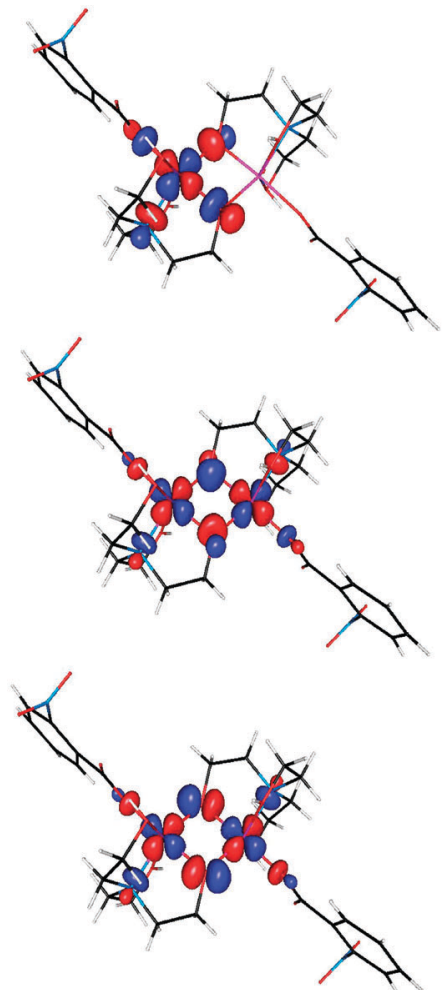

Fig. 11 Top: the "magnetic orbital" of one of the copper ions in 3. An orbital of the same shape is located also on the other copper ion. Center and bottom: the symmetric and antisymmetric combinations of the magnetic orbitals of two copper ions. The energy of the symmetric combination is lower by $2320 \mathrm{~cm}^{-1}$ than that of the antisymmetric combination. The overlap integral between the magnetic orbitals is 0.076. $E$ (High-Spin) $-E($ BrokenSym $)=-88.68 \mathrm{~cm}^{-1}$.

between structural parameters, in particular the $\mathrm{Cu}-\mathrm{O}-\mathrm{Cu}$ bond angle, and the $J$ value. In 3 , the obtained $J=-100 \mathrm{~cm}^{-1}$ is coupled with a $\mathrm{Cu}-\mathrm{O}-\mathrm{Cu}$ angle of $97.5(1)^{\circ}$, in line with what was found for similar dimeric complexes. ${ }^{39}$

In order to estimate the magnitude of the isotropic exchange integral $J$ in eqn (1)-(3), a DFT calculation has been performed using the procedure described in the previous section. Correct sign of $J$ was found while its magnitude was overestimated $\left(-176 \mathrm{~cm}^{-1}\right)$.

The interactions which contribute to ferromagnetism of dinuclear complexes involve pairs of overlapping 'magnetic orbitals' localized on each metal ion. ${ }^{40}$ Representative orbitals are plotted in Fig. 11.

As for EPR spectra, a spin-triplet $(S=1)$ spectrum was seen at all temperatures over the range 3-300 K. Spectra were of the best quality at moderately low temperatures of about $200 \mathrm{~K}$. Because of the large energy difference between the triplet and singlet states, the spectra could be interpreted in terms of the coupled-spin Hamiltonian with $S=1$ (instead of using eqn (3)):

$$
\hat{H}=\mu_{\mathrm{B}} B\{g\} \hat{\mathbf{S}}+D\left\{\hat{\mathbf{S}}_{z}^{2}-S(S+1) / 3\right\}+E\left(\hat{\mathbf{S}}_{x}^{2}-\hat{\mathbf{S}}_{y}{ }^{2}\right)
$$

Interestingly, the zero-field splitting tensor and the $g$ tensor were found to be non-coaxial. Spectra at all frequencies (Fig. 12)

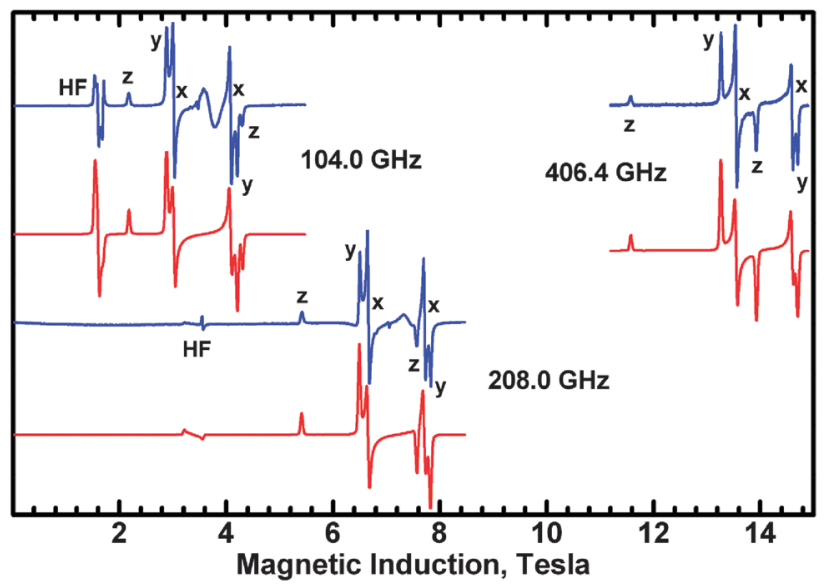

Fig. 12 High-frequency EPR spectra recorded at $200 \mathrm{~K}$ with the microwave frequencies as indicated. The blue and red traces are the experimental and simulated spectra, respectively. Labels $x, y$ and $z$ designate the magnetic field orientation at which the respective transitions occur. HF is the so-called half-field transition $\left(\Delta M_{S}=2\right)$. A feature between the $X$ resonances in the $104 \mathrm{GHz}$ spectrum is due to monomeric $\mathrm{Cu}^{2+}$ contamination. The spin Hamiltonian parameters are $g_{x}=2.060, g_{y}=2.060, g_{z}=$ 2.303, $D=-1.135 \mathrm{~cm}^{-1}, E=-0.0430 \mathrm{~cm}^{-1}$.

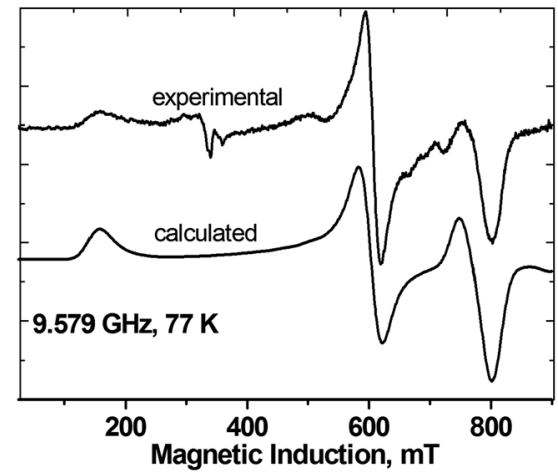

Fig. 13 The X-band EPR spectra of powdered complex 3 at $77 \mathrm{~K}$, experimental and calculated with the parameters given in the text.

were successfully simulated assuming that the zfs tensor is rotated versus the $g$ tensor by 11 degrees about the $X$ axis. At $200 \mathrm{~K}$, the following parameters were found: $g_{x}=2.060, g_{y}=$ $2.060, g_{z}=2.303, D=-1.135 \mathrm{~cm}^{-1}, E=-0.0430 \mathrm{~cm}^{-1}$. The parameters derived from the X-band spectra (Fig. 13) at $77 \mathrm{~K}$ are very similar: $g_{x}=2.06, g_{y}=2.06, g_{z}=2.30,|D|=1.125 \mathrm{~cm}^{-1},|E|=$ $0.040 \mathrm{~cm}^{-1}$, with signals due to the monomeric impurities present at $300 \mathrm{mT}$. The spin Hamiltonian parameters are temperaturedependent and at $10 \mathrm{~K}$ (Fig. 14) they are $g_{x}=2.056, g_{y}=2.045, g_{z}=$ $2.320, D=-1.042 \mathrm{~cm}^{-1}, E=-0.0075 \mathrm{~cm}^{-1}$, with the same angle of rotation of the zfs and $g$ tensors as found at $200 \mathrm{~K}(11 \mathrm{deg})$. The reason for the deviation between the axes of the $g$ and zfs tensors observed in the EPR spectra is the misalignment between the equatorial ligand plane and the $\mathrm{Cu}-\mathrm{Cu}$ direction.

Since the complex is ferromagnetic, EPR spectra could be detected at very low temperatures allowing determination of the sign of $D$ and $E .^{41}$ This is possible thanks to the Zeeman splitting being comparable to the thermal energy, $k T$ (Fig. 15). 


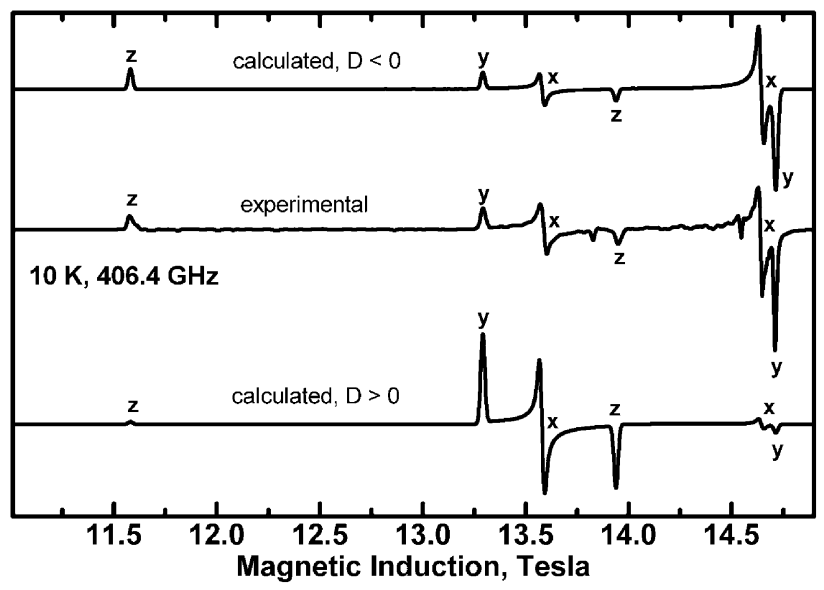

Fig. 14 Determination of the sign of the zero-field splitting parameters from the high-frequency EPR spectra recorded at $10 \mathrm{~K}$ with $\nu=406.4 \mathrm{GHz}$. The sign of $D$ and $E$ does not affect the positions of the resonance lines, but it does affect the intensity pattern at low temperatures and high frequencies. The spin Hamiltonian parameters at $10 \mathrm{~K}$ are: $g_{x}=2.056$, $g_{y}=2.045, g_{z}=2.320, D=-1.042 \mathrm{~cm}^{-1}, E=-0.0075 \mathrm{~cm}^{-1}$.

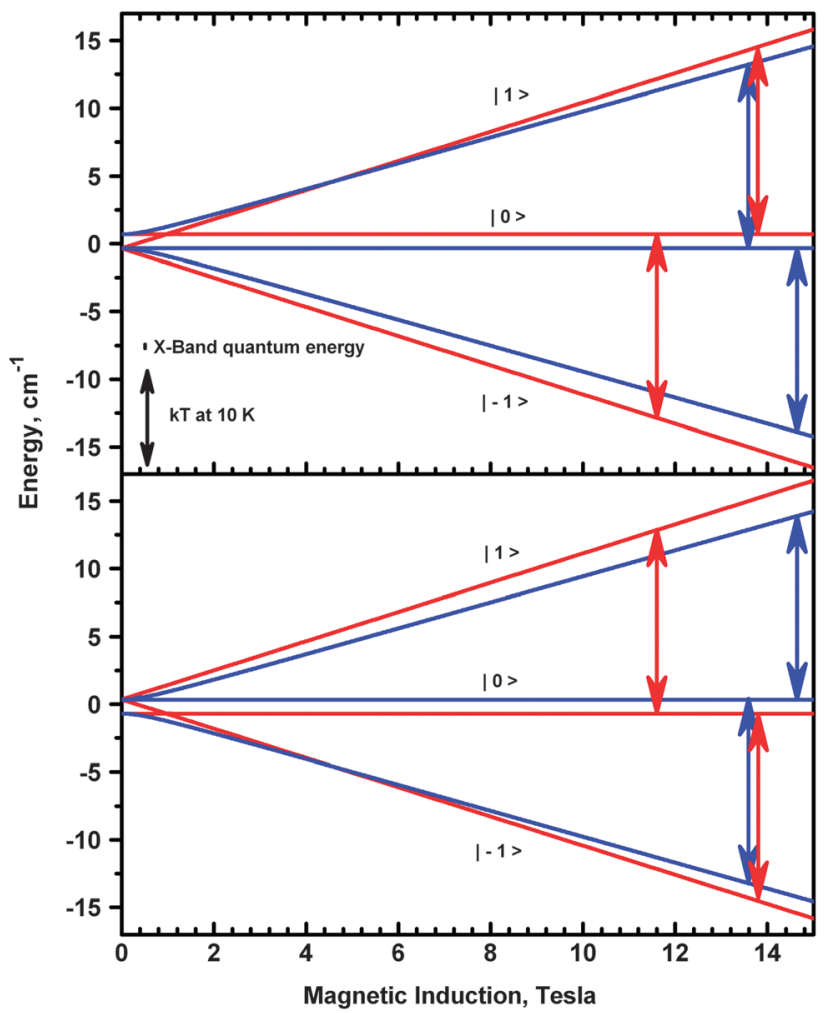

Fig. 15 Energy levels of the triplet state calculated with $D<0$ (top) and with $D>0$ (bottom). The red and blue lines represent the $Z$ and $X$ molecular orientation, respectively. The red and blue arrows have the length of the $406.4 \mathrm{GHz}$ microwave quantum energy $\left(13.55 \mathrm{~cm}^{-1}\right)$. With $D$ negative, the high-field transition at the $Z$ orientation (red arrow at $13.94 \mathrm{~T}$ ) starts from an excited level and its intensity will be suppressed at low temperatures, while the low-field transition intensity (11.57 T) will be enhanced. An opposite relationship holds for the transitions at the $\mathrm{X}$ orientation (blue arrows). If $D$ is positive, the energy diagram is reversed and all intensity relationships change to the opposite, while all resonance fields remain unchanged. Comparison of the $\mathrm{X}$-band microwave quantum energy $\left(0.32 \mathrm{~cm}^{-1}\right)$ to the thermal energy $\mathrm{kT}$ at $10 \mathrm{~K}$ $\left(6.95 \mathrm{~cm}^{-1}\right)$ indicates that no such effects can be observed in X-Band EPR.
In copper(II) dimers, there are two contributions to the zerofield splitting parameters $D$ and $E$. One is the magnetic dipoledipole interaction, while the other one is associated with the anisotropy of the exchange interactions. These contributions cannot be determined separately in an experiment. The dipolar part depends on the $\mathrm{Cu}-\mathrm{Cu}$ separation. Its largest component is oriented along the $\mathrm{Cu}-\mathrm{Cu}$ direction, while the largest component of the exchange-related zfs is expected to be parallel to the $g_{z}$ direction. The latter should be at least approximately perpendicular to the plane of the equatorial ligands. The angle between the $\mathrm{Cu}-\mathrm{Cu}$ vector and the normal to the equatorial ligand plane is $86 \mathrm{deg}$. We assume for simplicity that this angle equals $90 \mathrm{deg}$ and define a system of coordinates in which the axis $X$ is along $\mathrm{Cu}-\mathrm{Cu}$, and the axis $Z$ is perpendicular to $\mathrm{Cu}-\mathrm{Cu}$ and is tilted $4 \mathrm{deg}$ from the normal to the plane defined by the equatorial ligands. In these coordinates one can write formulae for the dipole-dipole related $D_{\text {dip }}$ and $E_{\text {dip }}$ parameters using the point-dipole approximation:

$$
\begin{gathered}
D_{\text {dip }}=\left(2 g_{z}^{2}+2 g_{x}^{2}-g_{y}^{2}\right) \mu_{\mathrm{B}}{ }^{2} / 4 R_{\mathrm{Cu}-\mathrm{Cu}}{ }^{3} \\
E_{\text {dip }}=-\left(2 g_{x}^{2}+g_{y}^{2}\right) \mu_{\mathrm{B}}{ }^{2} / 4 R_{\mathrm{Cu}-\mathrm{Cu}}{ }^{3}
\end{gathered}
$$

$D_{\text {dip }}$ and $E_{\text {dip }}$ above are pertinent to spin Hamiltonian (5). (Note that they need to be multiplied by 2 to be used in eqn (3).) With $R_{\mathrm{Cu}-\mathrm{Cu}}=2.92 \AA$ and our $g$ values we obtain $D_{\text {dip }}=0.0646 \mathrm{~cm}^{-1}$ and $E_{\text {dip }}=-0.0553 \mathrm{~cm}^{-1}$. These values should be considered as the upper limits, because the electron delocalization may considerably reduce them. ${ }^{42}$

The experimentally determined $D$ and $E$ parameters are the sum of the dipole-dipole and exchange-related parts, therefore

$$
\begin{gathered}
D_{\text {ex }}=D-D_{\text {dip }}=-1.20 \mathrm{~cm}^{-1} \\
E_{\text {ex }}=E-E_{\text {dip }}=0.007 \mathrm{~cm}^{-1}
\end{gathered}
$$

The exchange-related zero-field splitting thus appears to be remarkably axial $(|E| \ll|D|)$. Maurice et al. derived formulae for $D_{\text {ex }}$ and $E_{\text {ex }}$ for two coupled $\mathrm{Cu}^{2+}$ ions with the $\mathrm{d}_{x^{2}-y^{2}}$ ground state orbital. ${ }^{42}$

$$
\begin{aligned}
& D=2 \frac{\xi^{2} J_{x^{2}-y^{2}, x y}}{\Delta E_{x^{2}-y^{2}, x y}^{2}}-\frac{1}{4} \frac{\xi^{2} J_{x^{2}-y^{2}, x z}}{\Delta E_{x^{2}-y^{2}, x z}^{2}}-\frac{1}{4} \frac{\xi^{2} J_{x^{2}-y^{2}, y z}}{\Delta E_{x^{2}-y^{2}, y z}^{2}} \\
& E=\frac{1}{4} \frac{\xi^{2} J_{x^{2}-y^{2}, x z}}{\Delta E_{x^{2}-y^{2}, x z}^{2}}-\frac{1}{4} \frac{\xi^{2} J_{x^{2}-y^{2}, y z}}{\Delta E_{x^{2}-y^{2}, y z}^{2}}
\end{aligned}
$$

$\xi=-828 \mathrm{~cm}^{-1}$ is the spin-orbit coupling constant for $\mathrm{Cu}^{2+}$ and symbols like $J_{x^{2}-y^{2}, x y}$ are the exchange integrals between the $\mathrm{d}_{x^{2}-y^{2}}$ ground orbital of one copper ion and the excited $\mathrm{d}_{x y}$ orbital of another. The $d_{x z}$ and $d_{y z}$ orbitals of one copper are oriented similarly versus the $\mathrm{d}_{x^{2}-y^{2}}$ orbital of another copper atom. Accordingly, the terms in equations above involving $J_{x^{2}-y^{2}, x z}$ and $J_{x^{2}-y^{2}, y z}$ are expected to be of similar magnitude resulting in a small or equal to zero $E_{\text {ex }}$ parameter. With a different arrangement of the bridging group and $\mathrm{a}_{z^{2}}$ ground state of copper, very large $E$ values were observed. ${ }^{43}$ 
The quantities $\xi / \Delta E_{x^{2}-y^{2}, x y}$ etc. in eqn (7) appear also in the theory of the $g$ tensor in $\mathrm{Cu}$ (II). For example, $\Delta g_{z}=g_{z}-2.0023=$ $8 \xi / \Delta E_{x^{2}-y^{2}, x y}$ and it is possible to eliminate the unknown $\Delta E$ values from eqn (7):

$$
D_{\mathrm{ex}}=\left[J_{x^{2}-y^{2}, x y} \Delta g_{z}^{2}-2 J_{x^{2}-y^{2}, x z} \Delta \mathrm{g}_{y}^{2}-2 J_{x^{2}-y^{2}, y z} \Delta \mathrm{g}_{x}^{2}\right] / 32
$$

Also, $J_{x^{2}-y^{2}, x y}$ is expected to be the largest of the three $J_{x^{2}-y^{2}, n}$ exchange integrals. When the two remaining ones are neglected, one can estimate $J_{x^{2}-y^{2}, x y}=32 D_{\mathrm{ex}} / \Delta g_{z}^{2}=-425 \mathrm{~cm}^{-1}$. That exchange interaction is thus ferromagnetic, as expected, since the overlap integral of the copper orbitals is zero (a lobe of the $\mathrm{d}_{x y}$ orbital of one copper atom points between the positive and negative lobes of the $\mathrm{d}_{x^{2}-y^{2}}$ orbital of the other copper atom). $J_{x^{2}-y^{2}, x y}$ of the same order of magnitude were observed in copper dimers with similar bridging arrangement. ${ }^{44}$

\section{Conclusions}

Three novel complexes were isolated by addition of $\gamma$-picoline, $\beta$-picoline and triethanolamine to the hydrated copper(II) 2-nitrobenzoate, $\left.\left[\mathrm{Cu}_{2} \text { (2-nitrobenzoate }\right)_{4}\left(\mathrm{H}_{2} \mathrm{O}\right)_{2}\right] \cdot 2 \mathrm{H}_{2} \mathrm{O}$ suspended in a $4: 1$ methanol-water mixture. It has been found that the addition of different types of $\mathrm{N}$-donor ligands (rigid and flexible) has a profound influence on the orientation of $-\mathrm{NO}_{2}$ and $-\mathrm{COO}^{-}$ moieties in these complexes and, above all, on the coordination geometry around the $\mathrm{Cu}$ atom. Detailed structural analysis of 1, 2 and 3 confirms that the addition of different $\mathrm{N}$-donor ligands to copper(II) carboxylates may affect their physico-chemical behaviour such as magnetism. The dimeric complex 3 exhibits relatively strong ferromagnetic exchange with $J=-100 \mathrm{~cm}^{-1}$ (corresponding to $H=J S_{1} S_{2}$ ). The zero-field splitting parameters (zfs) of the dimer triplet state $D=-1.135 \mathrm{~cm}^{-1}, E=-0.043 \mathrm{~cm}^{-1}$ were derived from the HF EPR spectrum recorded at moderately low temperatures. The sign of $D$ was determined from lowtemperature HF EPR spectra.

\section{Acknowledgements}

The high-field EPR spectra were recorded at the NHMFL which is supported by the NSF through the cooperative agreement DMR-1157490, the State of Florida and the Department of Energy. One of us (RPS) thanks the U.G.C.(New Delhi), India, for financial assistance vide sanction letter F.No. 40-60/ 2011(SR). JJ is grateful to Ministry of Science and Higher Education of the Polish Republic for financial support in the purchase of the Bruker ELEXSYS E 500 EPR spectrometer.

\section{Notes and references}

1 (a) C. A. Schalley, Supramolecular Chemistry, Thematic Series, Beilstein J. Org. Chem., 2009, 5; (b) C. A. Schalley, Supramolecular Chemistry II, Thematic Series, Beilstein J. Org. Chem, 2011, 7; (c) H. Xu, X. Zhang, J. Sun and S. Cui, Supramolecular Chemistry: from molecular architecture to functional assemblies, Encyclopedia of Life Support System, 2010.

2 (a) C. S. Liu, P. Q. Chen, E. C. Yang, J. L. Tian, X. H. Bu, Z. M. Li, H. W. Sun and Z. Y. Lin, Inorg. Chem., 2006, 45, 5812; (b) J. W. Steed and P. A. Gale, Supramolecular Chemistry: From molecules to nanomaterials, Wiley, 2012, vol. 8.

3 (a) L. J. Zhou, Y. Y. Wang, C. H. Zhou, C. J. Wang, Q. Z. Shi and S. M. Peng, Cryst. Growth Des., 2007, 7, 300; (b) P. Diaz, J. Benet-Buchholz, R. Vilar and A. J. P. White, Inorg. Chem., 2006, 45, 1617.

4 S. H. Rahaman, H. Chowdhury, D. Bose, G. Mostafa, H.-K. Fun and B. K. Ghosh, Inorg. Chem. Commun., 2005, 8, 1041.

5 M. M. Bishop, S. J. Coles, H. W. L. Andrew, L. F. Linndoy, A. Parkin, O. T. Thorn-Seshold and P. Turner, Supramol. Chem., 2005, 17, 567.

6 J. Lang, K. Vagnerova, J. Czernek and P. Lhotak, Supramol. Chem., 2006, 18, 371.

7 J. P. Zhang and S. Kitagawa, J. Am. Chem. Soc., 2008, 130, 907.

8 A. Westcott, J. Fisher, L. P. Harding, P. Rizkallah and M. J. Hardie, J. Am. Chem. Soc., 2008, 130, 2950.

9 M. M. O. Pena, J. Lee and D. J. Thiele, J. Nutr., 1999, 129, 1251.

10 N. W. Solomons, J. Am. Coll. Nutr., 1985, 4, 83.

11 P. F. Larson, Angew. Chem., Int Ed., 2009, 48, 5091.

12 B. Wu, X.-J. Yang, C. Janiak and P. G. Lassahn, Chem. Commun., 2003, 902, and references cited therein.

13 J. R. J. Sorenson, Chem. Br., 1989, 25, 169, and references cited therein.

14 C. Marzano, M. Pellei, F. Tisato and C. Satini, Anticancer Agents Med. Chem., 2009, 9, 185.

15 I. Iakovidis, I. Delimaris and S. M. Piperakis, Mol. Biol. Int., 2011, 1.

16 Dublin Institute of Technology Intellectual Property Ltd, US Pat. EP2407164A1, 2012.

17 F. Q. Liu, Q. X. Wang, K. Jiao, F. F. Jian, G. Y. Liu and R. X. Li, Inorg. Chim. Acta, 2006, 359, 1524.

18 J. Moncol, M. Korabik, P. Segl'a, M. Koman, D. Mikloš, J. Jaškova, T. Glowiak, M. Melnik, J. Mrozinski and M. R. Sundberg, Z. Anorg. Allg. Chem., 2007, 633, 298.

19 M. Barceló-Oliver, Á. García-Raso, Á. Terrón, E. Molins, M. J. Prieto, V. Moreno, J. Martínez, V. Lladó, I. López, A. Gutiérrez and P. V. Escribá, J. Inorg. Biochem., 2007, 101, 649.

20 M. A. Malati, Experimental Inorganic Chemistry, Horwood Publishing, Chichester, 1st edn, 1999.

21 (a) C. J. O'Connor, Prog. Inorg. Chem., 1982, 29, 203; (b) G. A. Bain and J. F. Berry, J. Chem. Educ., 2008, 85, 532.

22 A. K. Hassan, L. A. Pardi, J. Krzystek, A. Sienkiewicz, P. Goy, M. Rohrer and L.-C. Brunel, J. Magn. Reson., 2000, $142,300$.

23 Z. Otwinowski and Z. Minor, Processing of X-Ray Diffraction Data Collected in Oscillation Mode, in Methods in Enzymology, ed. C. W. Carter and R. M. Sweet, Macromolecular Crystallography, Part A, Academic Press, San Diego, 1997, 307.

24 R. H. Blessing, Acta Crystallogr., 1995, A51, 33. 
25 A. Altomare, M. C. Burla, M. Camalli, G. Cascarano, C. Giacovazzo, A. Guagliardi, A. G. Moliterni, G. Polidori and R. Spagna, J. Appl. Crystallogr., 1999, 32, 115.

26 G. M. Sheldrick, SHELXL97, Program for Crystal Structure Refinement, University of Göttingen, Göttingen, Germany, 1997.

27 J. Farrugia, J. Appl. Crystallogr., 1999, 32, 837.

28 A. A. Granovsky, Firefly (PC GAMESS) version 7.1.G, Copyright (c) 1994, 2009, Firefly Project, Moscow, Russia.

29 M. W. Schmidt, K. K. Baldridge, J. A. Boatz, S. T. Elbert, M. S. Gordon, J. H. Jensen, S. Koseki, N. Matsunaga, K. A. Nguyen, S. Su, T. L. Windus, M. Dupuis and J. A. Montgomery, J. Comput. Chem., 1993, 14, 1347.

30 F. Neese, ORCA - An ab initio, Density Functional and Semiempirical Program Package, Version 2.9.1, 2012, free download from http://www.cec.mpg.de/forum/downloads. php; F. Neese, The ORCA program system WIREs, Comput. Mol. Sci., 2012, 2, 738.

31 (a) H. Schaefer, R. Horn and R. Ahlrichs, J. Chem. Phys., 1992, 97, 2571; (b) R. Ahlrichs, unpublished. The Ahlrichs auxiliary basis sets were obtained from the TurboMole basis set library under ftp.chemie.uni-karlsruhe.de/pub/jbasen.

32 (a) D. A. Becke, Phys. Rev. A, 1988, 38, 30980; (b) J. P. Perdew, Phys. Rev. B: Condens. Matter Mater. Phys., 1986, 33, 8822; (c) J. P. Perdew, Phys. Rev. B: Condens. Matter Mater. Phys., 1986, 34, 7406; (d) R. A. Kendall and H. A. Früchtl, Theor. Chem. Acc., 1997, 97, 158.

33 K. Nakamoto, Infrared and Raman Spectra of Inorganic and Coordination Compounds, John Wiley \& Sons, New York, 5th edn, 1997.

$34 \mathrm{~J}$. Bellamy, The Infrared Spectra of Complex Molecules, Chapman \& Hall, London/New York, 1980.

35 (a) A. M. Kirillov, M. N. Kopylovich, M. V. Kirillova, M. Haukka, M. F. C. G. da Silva and A. J. L. Pombeiro,
Angew. Chem., Int. Ed., 2005, 44, 4345; (b) R. M. Escovar, J. H. Thurston, T. Ould-Ely, A. Kumar and K. H. Whitmire, $Z$. Anorg. Allg. Chem., 2005, 631, 2867.

36 A. M. Kirillov, M. N. Kopylovich, M. V. Kirillova, E. Yu. Karabach, M. Haukka, M. F. C. G. da Silva and A. J. L. Pombeiro, Adv. Synth. Catal., 2006, 348, 159.

37 A. M. Kirillov, M. Haukka, M. N. Kopylovich and A. J. L. Pombeiro, Acta Crystallogr., 2007, E63, m526.

38 V. H. Crawford, H. W. Richardson, J. R. Wasson, D. J. Hodgson and W. E. Hatfield, Inorg. Chem., 1976, 15, 2107.

39 (a) W. E. Hatfield, in Magneto-structural correlations in exchange coupled systems, ed. R. D. Willet, D. Gatteschi and O. Kahn, NATO ASI Series., Reidel, Dordrecht, 1985, p. 555; (b) D. Venegas-Yazigi, D. Aravena, E. Spodine, E. Ruiz and S. Alvarez, Coord. Chem. Rev., 2010, 254, 2086; (c) E. Ruiz, P. Alemany, S. Alvarez and J. Cano, J. Am. Chem. Soc., 1997, 119, 1297.

40 (a) O. Kahn and B. J. Briat, J. Chem. Soc., Faraday Trans. 2, 1976, 72, 268; (b) A. Rodríguez-Diéguez, M. E. López-Viseras, J. E. Perea-Buceta, A. J. Mota and E. Colacio, Inorg. Chim. Acta, 2012, 385, 73; (c) N. Onofrio and J.-M. Mouesca, Inorg. Chem., 2011, 50, 5577; (d) A. Rodríguez-Fortea, P. Alemany, S. Alvarez and E. Ruiz, Inorg. Chem., 2002, 41, 3769.

41 (a) A. Ozarowski, Inorg. Chem., 2008, 47, 9760; (b) A. Ozarowski, I. B. Szymanska, T. Muziol and J. Jezierska, J. Am. Chem. Soc., 2009, 131, 10279.

42 R. Maurice, K. Sivalingam, D. Ganyushin, N. Guihery, C. de Graaf and F. Neese, Inorg. Chem., 2011, 50, 6229.

43 (a) D. L. Reger, A. E. Pascui, M. D. Smith, J. Jezierska and A. Ozarowski, Inorg. Chem., 2012, 51, 7966; (b) D. L. Reger, A. E. Pascui, M. D. Smith, J. Jezierska and A. Ozarowski, Inorg. Chem., 2012, 51, 11820.

44 A. Ozarowski and D. Reinen, Inorg. Chem., 1986, 25, 1704. 